\title{
Acidic Phospholipase A2-Peptide Derivative Modulates Oxidative Status and Microstructural Reorganization of Scar Tissue after Cutaneous Injury
}

\author{
Estefanny Ruiz García, ${ }^{1}$ Edvaldo Barros, ${ }^{2}$ Stephanie Stransky, ${ }^{3}$ Carlos Chávez-Olórtegui, ${ }^{3}$ \\ Mariella Bontempo Freitas, ${ }^{1}$ Rômulo Dias Novaes $\mathbb{D}^{4},{ }^{4}$ and Reggiani Vilela Gonçalves $\mathbb{D}^{1}$ \\ ${ }^{1}$ Department of Animal Biology, Federal University of Viçosa, Viçosa, MG, Brazil \\ ${ }^{2}$ Biomolecules Nucleus, Federal University of Viçosa, Viçosa, MG, Brazil \\ ${ }^{3}$ Department of Biochemistry and Immunology, Federal University of Minas Gerais, Belo Horizonte, MG, Brazil \\ ${ }^{4}$ Institute of Biomedical Science, Department of Structural Biology, Federal University of Alfenas, Alfenas 37130-001, MG, Brazil
}

Correspondence should be addressed to Reggiani Vilela Gonçalves; reggysvilela@yahoo.com.br

Received 29 February 2020; Accepted 1 June 2020; Published 11 July 2020

Academic Editor: Michel Mansur Machado

Copyright ( 2020 Estefanny Ruiz García et al. This is an open access article distributed under the Creative Commons Attribution License, which permits unrestricted use, distribution, and reproduction in any medium, provided the original work is properly cited.

\begin{abstract}
From in vitro and in vivo models, the proliferative and healing potential of an acidic phospholipase A2 (LAPLA2) from Lachesis muta venom was investigated. The LAPLA2 proliferative activity was evaluated on fibroblasts and keratinocytes cultured, and the antioxidant and regenerative potential of LAPLA2 was analyzed in a murine model. The animal study consisted of four groups: C (negative control): $0.9 \% \mathrm{NaCl}$; SS (positive control): $1 \%$ silver sulfadiazine; L1 group: 0.5\% LAPLA2; and L2 group: $0.25 \%$ LAPLA2. Wounds were topically treated daily for 12 days, and scar tissue samples were collected every 4 days. In vitro, LAPLA2 stimulated marked time-dependent cell proliferation. In vivo, it increased the antioxidant activity of superoxide dismutase (SOD) and catalase (CAT) and decreased malondialdehyde (MDA) and carbonyl protein (CP) levels in scar tissue treated with LAPLA2 at $0.5 \%$. This peptide was effective in stimulating cellular proliferation, neoangiogenesis, type I and III collagen deposition, and maturation in a time-dependent-way, reducing the time required for wound closure. Our results indicated that LAPLA2 presented a remarkable potential in improving the oxidative status and microstructural reorganization of the scar tissue by stimulation of cellularity, angiogenesis, colagenogenesis, and wound contraction, suggesting that the peptide could be a potential candidate for a new healing drug.
\end{abstract}

\section{Introduction}

Due to complexity and interdependence of all phases of wound healing (hemostasis, inflammation, proliferation, and remodeling), disturbances in tissue repair are not uncommon, especially when associated to metabolic (e.g., diabetes mellitus and vasculopathies) and microbial diseases (e.g., bacterial, fungal, and parasitic infections). As innate and acquired immunological mechanisms are integrated in the skin to provide microbiological protection, cutaneous wounds increase the risk of opportunistic infections, sepsis, and death $[1,2]$. Often disguised as a comorbidity, chronic wounds represent a silent epidemic, whose treatment is expensive, time-consuming, and not always successful $[3,4]$. Only in the United States of America, at least 28.1 billion dollars is spent annually to treat all categories of wounds [5]. In this sense, the high demand for more efficient treatments for skin wounds has stimulated the discovery and inclusion of synthetic and natural products in several research and development platforms [6-10].

Although poorly explored, animal bioactive substances have aroused growing biotechnological interest for the development of more effective healing drugs, especially due to their potent antimicrobial effects and high potential for 
stimulating cell proliferation and collagen biosynthesis $[11,12]$. Although small peptides secreted by honey bees [13] and anurans [14] are effective in accelerating the wound healing, little is known about whether and to what extent snake venom could be a source of bioactive products with potential applicability in regenerative medicine [15]. Currently, there is evidence, although limited, indicating that the antibacterial and antioxidant potential of proteins isolated from snake venom (e.g., disintegrins and phospholipases) are associated to their healing properties $[6,11,16]$. However, the impact of snake venom-isolated peptides on fibroblasts and keratinocytes proliferation, as well as collagen dynamics remains poorly understood, making it difficult to clarify its healing potential in skin wounds.

Transcriptional studies of the venom produced by the snake species Lachesis muta muta revealed a wide variety of protein families, such as metalloproteinases, phospholipases A2 (PLA2s), serine proteases, C-type lectin, bradykininpotentiating peptides (BPPs), and L-amino acid oxidases (LAAOs), all with potential biotechnological and pharmacological applicabilities [17]. PLA2 covers $8.7 \%$ of proteins in L. m. muta venom, and its hemolytic, neurotoxic, myotoxic, and proliferative effects have been described $[18,19]$. PLA2 superfamily includes five types of enzymes such as cytosolic, secreted, calcium-independent, lysosomal, and platelet-activating factors [20]. Snake venom PLA2s have been classified in the group I (in elapids) or II (in viperids) [21]. The PLA2s II are divided into two types, acidic Asp49-PLA2s, with the catalytic active activity and basic PLA2 homologues, and PLA2-like proteins that are catalytically inactive and usually possess a Lys49 substitution [22, 23]. Most of the acidic isoforms do not present toxic effects, a desirable characteristic considering its biological safety and pharmacological relevance [24].

In order to address the need for more effective treatments, and considering that L. m. muta venom is a viable source rich in bioactive peptides with antimicrobial, immunomodulatory, and healing potential, we isolated an acidic phospholipase A2 (LAPLA2) produced by this species and used in vitro- and in vivo-integrated approaches to investigate the effect of this molecule on fibroblasts and keratinocytes proliferation, angiogenesis, colagenogenesis, antioxidant defenses, and wound closure in a murine excisional wound model. We hypothesized that snake venom may be a valuable source of bioactive molecules with potential applicability in regenerative medicine.

\section{Material and Methods}

2.1. Venom, Purified Fraction. Crude venom of L. m. muta and its purified fraction were donated by the Immunochemistry of Proteins Laboratory of the Federal University of Minas Gerais (Belo Horizonte, Brazil). Briefly, for molecular exclusion chromatography, L. m. muta venom was purified according to the method used by Flores-Sánchez et al. [25]. The venom was applied to a Superdex ${ }^{\mathrm{TM}} 75 \mathrm{HR} 10 /$ 30 column (Pharmacia), previously, equilibrated with $50 \mathrm{mM}$ ammonium acetate buffer, $\mathrm{pH}$ 6. Elution was carried out using the same buffer. Fractions were monitored through spectrophotometry at $280 \mathrm{~nm}$. Samples were stored at $4-20^{\circ} \mathrm{C}$ until its use (unpublished results).

2.2. Electrophoresis and Mass Spectrometry. Protein quantification in the purified venom was performed according to Lowry [26]. In order to estimate the molecular weight of the proteins, $40 \mu \mathrm{g}$ of venom fraction was analyzed using SDSPAGE (15\%) following the method of Laemmli [27]. Protein samples were analyzed under reducing conditions. The gel was stained with colloidal Coomassie Blue G-250 (Sigma Aldrich, St. Louis, MO, USA).

The banding pattern visualized in the SDS-PAGE was subjected to trypsinization according to the protocol described by Olsen [28]. Peptide mass spectra (MS and MS/ MS) were obtained using MALDI-TOF/TOF. The MALDI analysis was performed using an $\alpha$-cyano-4-hydroxycinnamic matrix and an Ultraflex III MALDI-TOF/TOF mass spectrometer (matrix-assisted laser desorption/ionization time-of-flight) (Bruker Daltonics, Bremen, Germany). The MS analysis was performed with reflective positive mode, while the MS/MS analysis used the LIFT positive mode.

\subsection{Spectrum Analysis and Protein Identification. Protein} identification was performed using MASCOT DAEMON 2.2 software (Matrix Science, Boston, MA, USA) in the MS/MS ion search mode, following digestion with trypsin, accepting one missed cleavage, and adopting a mass error tolerance of 0.2 Da for the MS mode and 0.5 Da for the MS/MS mode. Cysteine carbamidomethylation was used as the fixed modification and methionine oxidation as the variable. The database used was Metazoa (downloaded in 09/22/2016, with $8,585,752$ entries), deposited in UniProt consortium. Protein identification validation was performed using the software MASCOT (SCAFFOLD) version 3.6.4 (Proteome Software, Portland, OR, USA). For validation, the following parameters were accepted: peptides identification score $\geq 90 \%$ for both peptides [29] and proteins [30], with at least two validated peptides per protein. Four available sequences corresponding to acidic Asp49-PLAs were characterized from the Viperidae family, with an identity of at least $34 \%$ in comparison to the partial sequence of the purified protein, using a BLAST search (http://blast.ncbi.nlm.gov). These proteins were aligned with the program MUSCLE [31] using MEGA v7.0.25 software [32] and the maximum likelihood method based on the JTT matrix-based model [33].

\subsection{Fibroblasts and Keratinocytes Viability and Proliferation} Assays. Fibroblasts (3T3 lineage) and keratinocytes (HaCaT lineage) were culture in Dulbecco's modified Eagle's medium (DMEM, Sigma Aldrich, St. Louis, MO, USA), supplemented with $10 \%$ fetal bovine serum (Sigma Aldrich) and $0.2 \%$ gentamycin (Gilbco by Life Technologies). Cells were maintained in a controlled atmosphere, at $37^{\circ} \mathrm{C}$ with $10 \%$ $\mathrm{CO}_{2}$. In the cell viability assay, $\mathrm{HaCaT}$ and $3 \mathrm{~T} 3$ cells were plated in 96 well plates at $10^{4}$ cells /well and incubated for $24 \mathrm{~h}$ at $37^{\circ} \mathrm{C}$ and $10 \% \mathrm{CO}_{2}$. Then, cells were incubated with different concentrations of L. m. muta crude venom or its 
purified fraction $(1.25-20 \mu \mathrm{g} / \mathrm{mL})$. After the incubation period, the culture supernatant was removed, and Alamar Blue $(10 \% \mathrm{v} / \mathrm{v})$ was added to each well, according to the protocol described by Damico [34], with modifications. The plate was incubated for 3 hours, and the produced fluorescence was measured using Synergy 2 (BioTek) at $540 \mathrm{~nm}$ for excitation and $590 \mathrm{~nm}$ for emission. For analysis of cell proliferation, cells were incubated with two different concentrations of LAPLA2 $(10$ and $20 \mu \mathrm{g} / \mathrm{mL})$ or crude venom for 24,48 , and 72 hours.

2.5. Animals and Ethics. Male Swiss-Webster mice $(n=36,7$ weeks old) weighing $25 \pm 5 \mathrm{~g}$ were used in the model of excisional skin injury. Mice were allocated in individual cages cleaned daily, which were maintained under a controlled environment with $12: 12 \mathrm{~h}$ light/dark conditions, $22 \pm 2^{\circ} \mathrm{C}$ temperature, and 60-70\% humidity. Rodent diet and water were provided ad libitum. All the procedures used in this study were approved by the Ethics Committee of Animal Experimentation of the Federal University of Viçosa (registration 365/2015).

2.6. Experimental Design. Prior to creating the wounds, animals were anesthetized by intraperitoneal injection of pentobarbital $(70 \mathrm{mg} / \mathrm{kg}$ b.w.). Dorsolateral shaving of the animals was performed, and the area was degreased with ethyl ether (Merck, Rio de Janeiro, RJ, Brazil), followed by the use of $70 \%$ ethanol and $10 \%$ povidone-iodine for antisepsis (Johnson Diversey, Rio de Janeiro, RJ, Brazil). One circular wound with $10 \mathrm{~mm}$ in diameter was made with a scalpel in the skin until the dorsal muscular fascia was exposed [35]. Animals were randomly distributed in four groups ( $n=9$ per group): $\mathrm{C}$ (negative control): $0.9 \% \mathrm{NaCl}$ solution; SS (positive control): $0.6 \mathrm{~g}$ of silver sulfadiazine (1\%), L1 group: $5 \mu \mathrm{L}$ of LAPLA2 diluted in Milli $Q$ water $(100 \mu \mathrm{L})(0.5 \%)$; and L2 group: $5 \mu \mathrm{l}$ of LAPLA2 diluted in Milli $Q$ water $(200 \mu \mathrm{L})(0.25 \%)$. The concentration of the PAPLA2 was chosen based on the in vitro analysis. These concentrations showed best results for protecting the cells, showing decrease in the death of epithelial cells. All wounds were cleaned daily with $0.9 \%$ saline solution before each treatment. Wounds were topically treated daily for 12 days. Over this period, the time-dependent healing process was evaluated from the scar tissue collected every 4 days from three animals per group.

2.7. Wound Contraction Assay. The time-dependent wound closure was evaluated by measuring the wound area every 4 days in digitized images with the dimensions of $320 \times 240$ pixels (24 bits/pixel), obtained using a digital video camera (W320, Sony, Tokyo, Japan). The wound area was calculated by computerized planimetry using the software Image ProPlus, version 4.5 (Media Cybernetics, Silver Spring, USA), previously calibrated. The Wound Contraction Index (WCI) was calculated using the following ratio: initial area of the wound (Ao)-area measured on a given day (Ai)/initial area of the wound $(\mathrm{Ao}) \times 100$ [35]. The photos were standardized by the use of camera holder with standardized distance, and this procedure was performed for all the groups. The animals were sedated during this procedure.

2.8. Microstructural Analysis of Tissue Cellularity, Blood Vessels, Collagen Fibers, and Mast Cells. Skin sections were immersed in Karnovsky fixative for $24 \mathrm{~h}$, dehydrated in ethanol, diaphanized in xylene, and embedded in paraffin. Histological sections with $5-\mu \mathrm{m}$ thickness were obtained using a rotary microtome (Leica Multicut 2045, ReichertJung Products, Jena, Germany) and stained with hematoxylin and eosin ( $\mathrm{H} \& \mathrm{E}$ ) for analysis of tissue cellularity and blood vessel [36]. Scar tissue sections stained with toluidine blue were used for mast cells identification and quantification [37]. Sirius red (Sirius red F3B, Mobay Chemical Co., NJ, USA) was used for the collagen analysis. Collagen fibers were characterized and quantified from differential properties of birefringence under polarized light, in which thick collagen fibers (type I) appear in shades of bright colors ranging from red to yellow, whereas the thin reticular fibers (type III) appear bright green [38, 39].

Images were captured using a BX-60 bright-field photomicroscope (Olympus, Tokyo, Japan). Stereological parameters of volumetric density ( $\mathrm{Vv}$ ) were calculated by counting the points over fibroblasts, blood vessels, and type I and type III collagen, using the ratio $\mathrm{Vv}=\mathrm{PP} / \mathrm{PT}$, in which $\mathrm{PP}$ is the number of points occurring over the structure of interest, and PT is the total number of points on the test system [40]. For this analysis, a grid containing 500 points within a standard test area (TA) of $73.10^{3} \mu \mathrm{m}^{2}$ at the tissue level was used. The number of mast cells per unit of histological area was calculated according to the notation $\mathrm{QA}=\Sigma$ mast cells/TA [41]. Ten histological fields were randomly sampled in each skin section using a 20x objective lens, and all microstructural parameters were analyzed in a total tissue area of $6.21 \times 10^{6} \mu \mathrm{m}^{2}$. The Image Pro-Plus software (Media Cybernetics, Silver Spring, USA), was used in all quantifications [35].

2.9. Endogenous Antioxidant Enzymes Assay. Tissue fragments were collected from each wound, rapidly frozen in liquid nitrogen, and stored at $-80^{\circ} \mathrm{C}$. Samples were homogenized in phosphate buffered saline (PBS) and centrifuged at $5^{\circ} \mathrm{C}[42,43]$. The supernatant was used for the analysis of superoxide dismutase (SOD) and catalase (CAT). The SOD activity was estimated by a method based on the production of $\mathrm{H}_{2} \mathrm{O}_{2}$ by xanthine oxidase and reduction of nitroblue tetrazolium, according to the protocol described by Siddiqui [44]. The CAT activity was measured by measuring the rate of decomposition of hydrogen peroxide $\left(\mathrm{H}_{2} \mathrm{O}_{2}\right)$ according to Aebi [45]. The enzymatic activity was normalized by the total protein levels in the supernatant, quantified according to the method described by Bradford [46].

2.10. Lipid and Protein Oxidation Assay. For the analysis of malondialdehyde (MDA), an end product of lipid peroxidation, the same supernatant was reacted with thiobarbituric acid, and the formation of thiobarbituric acidreactive substance was monitored at $535 \mathrm{~nm}$ in accordance 
with the protocol described by Gutteridge and Halliwell [47]. Carbonyl proteins (CP), a direct marker of protein oxidation, were analyzed from the derivatization of the carbonyl group with 2, 4-dinitrophenylhydrazine (DNPH), which leads to the formation of a stable 2, 4-dinitrophenyl (DNP) hydrazone product. CP levels were measured by spectrophotometry at $370 \mathrm{~nm}$ according to the protocol described by Jana [48]. The results of MDA and CNP data were equally normalized by the total protein levels [46].

2.11. Statistical Analysis. Results are expressed as mean and standard deviation (mean $\pm \mathrm{SD}$ ). Comparisons among data with normal distribution were performed using one-way ANOVA followed by the Student-Newman-Keuls post hoc test. Nonparametric data were compared by the Kruskal-Wallis test. Statistical significance was set at $P<0.05$.

\section{Results}

3.1. LAPLA2 Isolated from Snake Venom. LAPLA2 showed a band between $\sim 12 \mathrm{kDa}$ and $\sim 17 \mathrm{kDa}$. After enzymatic digestion of the visualized protein, tryptic peptides were shown on the MS spectrum (Figure 1(a)). The obtained sequence represents $\sim 35 \%$ of the protein sequence (Figure 1(b)). The peptides $\mathrm{m} / z 1298.698$ (HLLQFGDLIDK), $\mathrm{m} / z 1814.733$ (EICECDRDAAICFR), and $\mathrm{m} / z 2169.875$ (SGFWYYGFYGCYCGLGGR) were fragmented and aligned with the acidic phospholipase $A_{2}\left(\mathrm{PA}_{2} \mathrm{~A}\right)$ sequence of Lachesis stenophrys (Figure 1(c)). The MASCOT result showed that LAPLA2 identification was highly reliable, with a score of 226, significance $>51$, and $P<0.05$. The peptides were validated by SCAFFOLD software (Table S1). The BLAST analysis showed sequence homology with other acidic phospholipases of viperid snakes, and three conserved domains (PA2c, Phospholip_A2_1, and PLA2c) were identified. The alignment showed that the partial sequence of LAPLA2 was identical to a Lachesis stenophrys sequence, showing high homology (Figure S2).

3.2. Cell Viability and Proliferation In Vitro. The treatment of 3T3 fibroblasts with crude venom decreased cell viability $(P<0.01)$, whereas LAPLA2 did not affect cell viability (Figure 2(a)). In HaCaT keratinocytes, the highest concentration of crude venom $(20 \mu \mathrm{g} / \mathrm{mL})$ induced a decrease (59\%) in cell viability $(P<0.01)$, whereas HaCaT keratinocytes treated with LAPLA2 were $100 \%$ viable in all concentrations tested (Figure 2(b)). In relation to cell proliferation, with $10 \mu \mathrm{g} / \mathrm{mL}$ of LAPLA2, increased keratinocytes proliferation was observed when compared to crude venom $(P<0.01)$. In contrast, the cells treated with LAPLA2 at $20 \mu \mathrm{g} / \mathrm{ml}$ did not present a progressive increase in cellularity, but maintained the cell viability when compared to crude venom $(P<0.01)$ (Figure 3$)$.

3.3. Wound Area and Contraction. All wounds were performed in aseptic condition, and no evidence of infection was detected. Time-dependent wound contraction was clearly observed in all groups of treatment. Wound area was significantly reduced in the L1 group in day 8 and day 12 $(P<0.01)$ compared with the $\mathrm{C}$ group. While the WCI was significantly higher in the L1 group, compared with the $\mathrm{C}$ group in days 8 and $12(P<0.05)$ (Table 1$)$.

3.4. Tissue Cellularity and Vascularization in the Scar Tissue. LAPLA2-treated animals showed an increase on tissue cellularity compared to the SS group on day 4 . At day 8 , the L2 group showed increased cellularity when compared to the other groups. On day 12, the two treatment groups showed decreased cellularity compared to the control $(P<0.001)$, and the L2 group showed decreased values compared to the SS group $(P<0.001)$ (Figure $4(\mathrm{a}))$.

After 4 days, the L1 group showed an increase in blood vessel density compared to the groups control, SS, and L2 $(P<0.05)$. At day 8 , blood vessel density increased in L1, L2, and SS groups compared to the control group $(P<0.05)$. On day 12, the density of blood vessels decreased in L1 and L2 groups compared to the groups control and SS $(P<0.05)$ (Figure $4(\mathrm{~b})$ ). In mast cells, there was a significant increase in the L2 group compared to the control group $(P<0.05)$ at the day four. L1 and L2 groups also increased significantly at day 8 compared to the SS group $(P<0.001)$. At day 12 , the number of mast cells for SS, L1, and L2 groups remained high in the LAPLA2-treated groups when compared to the control (Figure 4(c)). The advanced healing process in the scar tissue of mice treated with LAPLA2 is represented in Figure 5.

3.5. Collagen Deposition in the Scar Tissue. At day 4, type III collagen was higher in L1, L2, and SS groups when compared to control animals $(P<0.05)$. At day 8 , a greater deposition of type III collagen was observed in the SS group. At day 12, the same parameter was increased in L1 and SS groups compared to the control group and L2 group $(P<0.05)$ (Figure 6(a)). At day 8, the L1 group showed an increase in type I collagen fibers deposition compared to control and SS groups $(P<0.05)$, while the L2 group presented higher values when compared to control and SS groups $(P<0.001)$. At day 12, type I collagen deposition was higher in the L1 group when compared to control and SS groups $(P<0.001)$. In the same day, the L2 group presented higher values than SS and control groups $(P<0.01)$ (Figure 6(b)). Control and SS groups showed a marked distribution of type III collagen fibers (green), while L1 and L2 groups presented a predominance of type I collagen fibers (yellow/red) (Figure 7).

3.6. Activity of Antioxidant Enzymes in the Scar Tissue. The activity of SOD was higher at day 4 in the L1 group compared to L2, SS, and control groups $(P<0.001)$. The SOD activity was significantly higher in the control than SS and L2 animals $(P<0.05)$. At day 8 , the L2 group showed a higher SOD activity when compared to the others groups $(P<0.001)$ (Figure $8(\mathrm{a}))$. The CAT activity increased at day 8 in the L2 group compared to L1, SS, and C groups $(P<0.05)$. The CAT activity was also higher in the control than that in L1 animals $(P<0.05)$. At day 12, CAT levels from the L2 


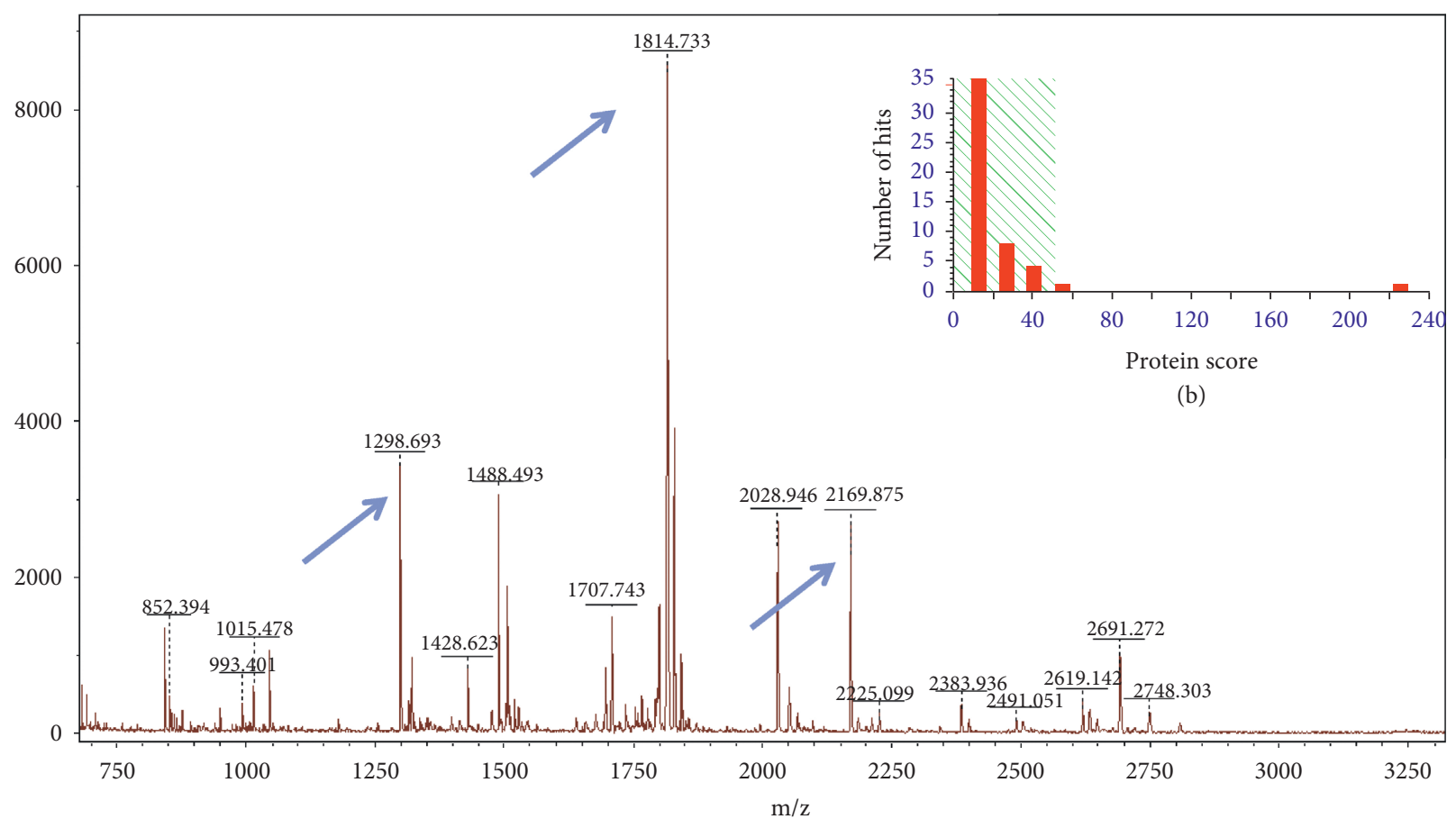

(a)

>sp|P84651| PA2A_Acidic phospholipase A2 of Lachesis stenophrys HLLQFGDLIDKIAGRSGFWYYGFYGCYCGLGGRGRPQDATDR CCFVHDCCYGKVTGCDPKKDIYTYSEENGAIVCGGDNPCKKE ICECDRDAAICFRDNLDTYDNKYWLFPNKYCKEESEPC

(c)

FIGURE 1: (a) MS1 of the L17 snake venom fraction, indicating in the blue arrows the peaks that followed for MS2 and matched with a protein in the database studied. (b) Mascot histogram with protein score represented by 216 bar. Individual ions scores $>51$ indicated identity or extensive homology $(P<0.05)$. (c) Tryptic peptides sequence identified and aligned in the complete sequence of PA2A of L. stenophrys.

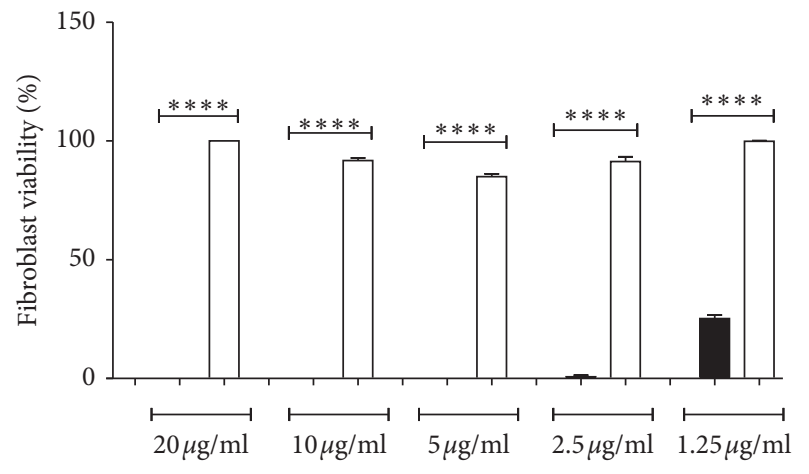

(a)

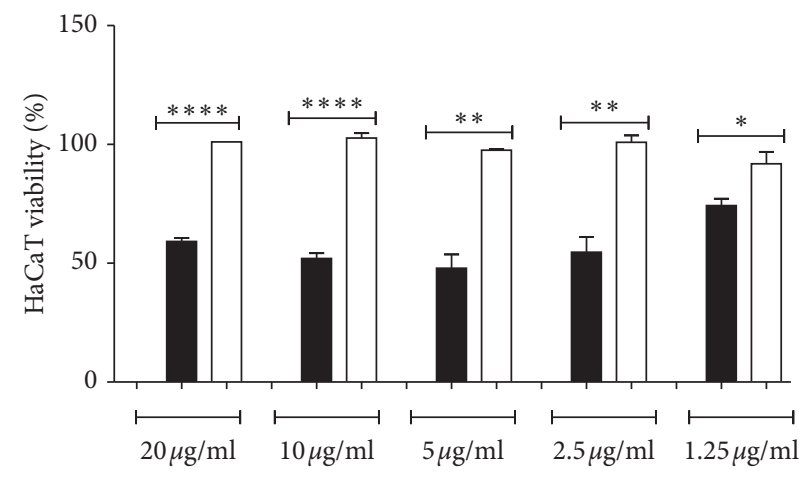

(b)

Figure 2: Effect of crude snake venom and isolated LAPLA2 on 3T3 fibroblast (a) and HaCaT keratinocytes (b) viability. Data are presented as mean \pm standard deviation. Statistical differences ${ }^{*} P<0.05$, ${ }^{* * *} P<0.001$, and ${ }^{* * * *} P<0.001$.

group remained higher compared to SS and L1 groups $(P<0.05)$ (Figure 8(b)).

3.7. Lipid and Protein Oxidation in the Scar Tissue. At day 4, MDA levels were decreased in L1, L2, and control groups as compared to the group SS $(P<0.001)$. At day 12 , MDA levels were decreased in SS, L1 and L2 groups as compared to that in control animals $(P<0.05)$ (Figure $9(\mathrm{a}))$.

The levels of carbonyl proteins were decreased in SS, L1, and L2 groups $(P<0.001)$ on days 4 and 8 compared to the control group. On day 12, CP levels were decreased in the L2 group compared to control and SS groups $(P<0.05)$ (Figure 9(b)). 


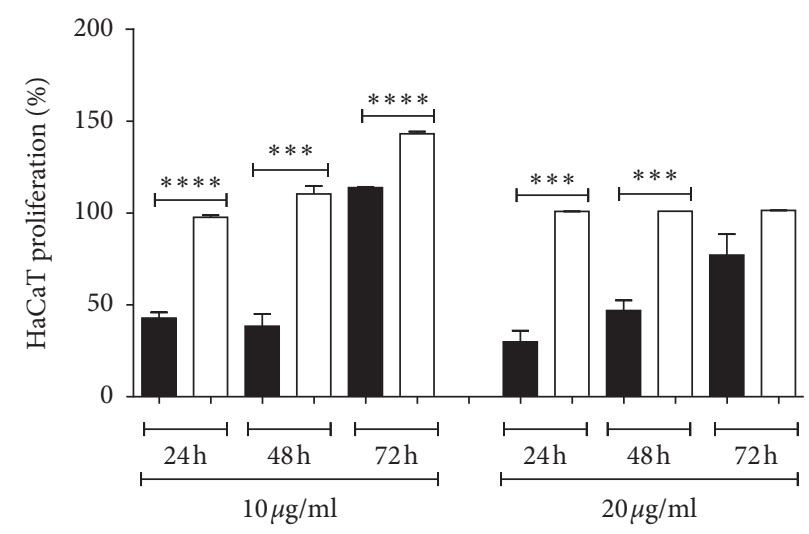

FIGURe 3: Effect of crude snake venom and isolated LAPLA2 on HaCaT keratinocytes proliferation. Data are presented as mean \pm standard deviation. Statistical differences compared to the group (C) statistical difference ${ }^{* * *} P<0.001$ and ${ }^{* * * *} P<0.001$.

TABle 1: Wound area $\left(\mathrm{mm}^{2}\right)$ and the Wound Contraction Index (WCI) (\%) in animals treated with different concentrations of LAPLA2.

\begin{tabular}{|c|c|c|c|c|c|}
\hline Day & Area/Contraction & $\mathrm{C}$ & SS & L1 $0.5 \%$ & L2 $0.25 \%$ \\
\hline \multirow{2}{*}{0} & Area $\left(\mathrm{mm}^{2}\right)$ & $110.00 \pm 0.00$ & $100.00 \pm 0.00$ & $105.00 \pm 0.00$ & $108.00 \pm 0.00$ \\
\hline & WCI (\%) & $00.00 \pm 00.00$ & $00.00 \pm 00.00$ & $00.00 \pm 00.00$ & $00.00 \pm 00.00$ \\
\hline \multirow{2}{*}{4} & Area $\left(\mathrm{mm}^{2}\right)$ & $76.66 \pm 9.42$ & $83.33 \pm 9.42$ & $60.00 \pm 21.60$ & $80.00 \pm 8.16$ \\
\hline & WCI (\%) & $30.30 \pm 10.49$ & $16.66 \pm 11.54$ & $42.85 \pm 25.19$ & $25.92 \pm 9.25$ \\
\hline \multirow{2}{*}{8} & Area $\left(\mathrm{mm}^{2}\right)$ & $70.00 \pm 16.32$ & $53.33 \pm 12.47$ & $23.33 \pm 4.71^{* *}$ & $46.66 \pm 12.47$ \\
\hline & WCI (\%) & $36.36 \pm 18.1$ & $46.66 \pm 15.27$ & $77.77 \pm 5.49^{*}$ & $56.79 \pm 14.14$ \\
\hline \multirow{2}{*}{12} & Area $\left(\mathrm{mm}^{2}\right)$ & $20.00 \pm 00.00$ & $13.33 \pm 4.71$ & $6.66 \pm 4.71^{* *}$ & $11.66 \pm 2.35$ \\
\hline & WCI (\%) & $81.81 \pm 00.00$ & $86.66 \pm 5.77$ & $93.65 \pm 5.49^{*}$ & $89.19 \pm 2.67$ \\
\hline
\end{tabular}

C group: saline solution (0.9\%), SS group: silver sulfadiazine (1\%), L1 group: LAPLA2 (0.05\%), L2 group: LAPLA2 (0.25\%). Data are presented as mean \pm SD. Statistical differences compared to the group $C,{ }^{*} P<0.05$ and ${ }^{* *} P<0.01$.

\section{Discussion}

In the present study, we identified the healing effect of a phospholipase obtained from the venom of the snake $L . m$. muta. Our results showed that LAPLA2 does not affect the viability of fibroblasts and keratinocytes; on the contrary, it promotes cell proliferation. In addition, we found a decrease in wound area and an increase in cellularity and angiogenesis. The protein also stimulated the collagen deposition during the healing process and showed to have an antioxidant effect on the tissue. Furthermore, this work adds more information on the phospholipases found in the Lachesis genus by the identification of the new sequences and homologies.

Our results showed that LAPLA2 does not affect fibroblast and keratinocytes viability, indicating no evidence of toxicity in these integumentary lineages. Interestingly, LAPLA2 stimulated keratinocytes proliferation and modulated the morphofunctional dynamics of the scar tissue, accelerating wound contraction, and cutaneous repair. Another acid phospholipase isolated from the snake Bothrops atrox was shown to increase the inflammatory process, playing a role in the development of regional and systemic toxicity after exposure to venom [49]. On the other hand, PLA2s isolated from B. asper were also shown to be free of any toxic effect, although a slight edema was reported in treated animals, with no effects on the coagulation cascade or platelet aggregation [50]. Another acidic PLA2 isolated from Porthidium lansbergii lansbergii venom counteracted the toxic effects of the basic PLA2 isolated from the same snake [51].

Differently to the LAPLA2 effect in cell viability, our findings confirmed that L. m. muta crude venom was cytotoxic to fibroblasts, decreasing cells viability in culture. In addition, 50\% reduction in HaCaT keratinocytes viability was clearly detected, indicating that these cells show partial resistance against all concentrations of venom used in the in vitro assays. This resistance was also observed in previous studies with HaCaT keratinocytes, which exhibited $70 \%$ cell viability under treatments at high doses $(60 \mu \mathrm{g} / \mathrm{mL})$ of Montivipera bornmuelleri crude venom [52]. These findings corroborate the cytotoxic effect of this crude venom and the evidence that different cell populations of the integument have different resistance and susceptibility profiles to compounds present in snake venom $[52,53]$. Therefore, it is prudent and advisable to investigate different cell types to evaluate the pharmacological potential and cytotoxicity risks associated with the different derivatives obtained from viperids' venom.

The proliferative stimulation of LAPLA2 on keratinocytes was consistent with our in vivo findings, indicating that this molecule was potentially effective in stimulating cell migration and proliferation in the scar tissue during the initial phases of wound healing (inflammatory and proliferative). Increased tissue cellularity is directly related with a marked inflammatory process and a better reepithelialization, which is potentiated when the wound closure is 


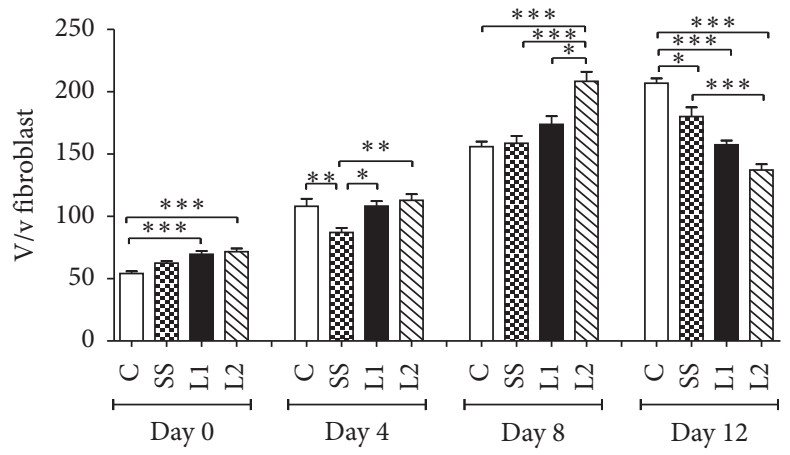

(a)

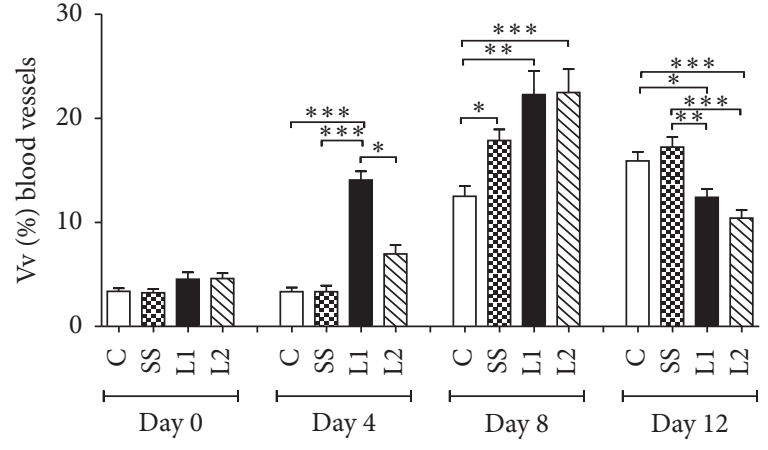

(b)

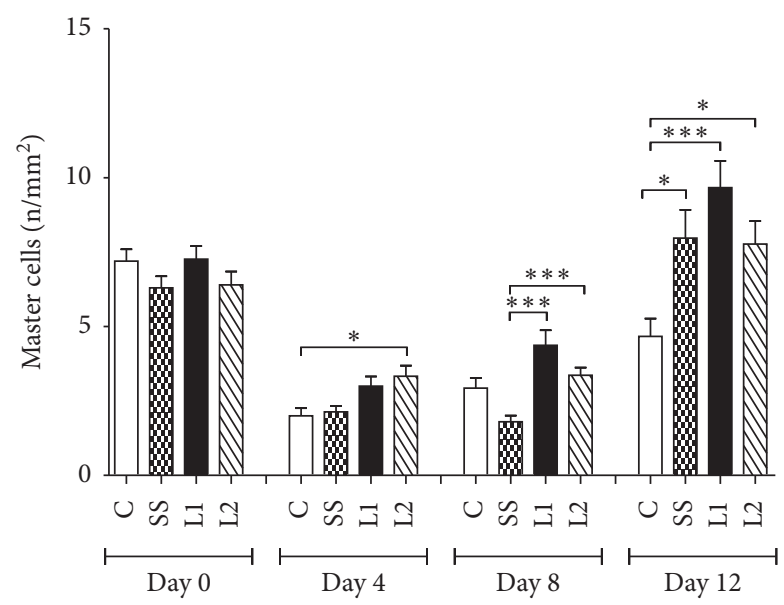

(c)

Figure 4: Proportion of fibroblasts (a), blood vessels (b), and mast cells (c) in the scar tissue of mice treated with LAPLA2 isolated from snake venom. C group: saline solution (0.9\%), SS group: silver sulfadiazine (1\%), L1 group: LAPLA2 (0.5\%), and L2 group: LAPLA2 (0.25\%). Data are presented as mean \pm standard deviation. Statistical differences compared to the group (c) ${ }^{*} P<0.05,{ }^{* *} P<0.01$, and ${ }^{* * *} P<0.001$.

accelerated by healing products $[54,55]$. Previous evidence indicates that proteins isolated from viperids' venoms are also able to induce a proliferative effect on retinal ganglion cells. Da Silva Cunha et al. [18] showed that the pharmacological potential of snake venoms derivatives is not restricted to integument cells. In addition to stimulating cell proliferation in the initial phases of wound healing, the effect of LAPLA2 extended to the later phase of tissue repair, contributing to the proper balance between cells and ECM components. In the remodeling stage, reduction of the inflammatory process and tissue cellularity, as well as intense colagenogenesis, are essential events, enhancing the strength and resistance of newly formed tissue [56-58]. Thus, by modulating both phases of wound healing, a faster wound closure in animas treated with LAPLA2 was expected, confirming its remarkable bioactive effect, with biotechnological potential in regenerative medicine.

Apart from fibroblasts and keratinocytes, mast cells also contribute to skin wound healing and are important effectors of the cutaneous immunological response [59, 60]. Although their role in the healing process is still not completely understood, studies have suggested that these cells have an implication in neovascularization by secreting stimulatory molecules such as cytokines (i.e., IL-1, TGF- $\beta$, and TNF- $\gamma$ ) and grown factors (i.e., FGF and VEGF) [61,62]. During the late phase of healing, a high number of mast cells on the edge of the wound stimulate degradation of thin collagen fibers (i.e., type III) by matrix metalloproteinases and colagenogenesis (especially mediated by FGF and TGF$\beta$ ), playing a direct role in the reorganization of the fibrous matrix and morphofunctional remodeling of the skin [63, 64]. Mast cells also promote the recruitment of neutrophils after an injury, which play an important role on the scar tissue formation, and their lack is associated with delays in the healing process [65]. Our results show that LAPLA2 increased the distribution of mast cells in the wound edge, which is potently associated with an improved leucocytes recruitment, angiogenesis, colagenogenesis, and reorganization of collagen fibers, modulating the healing dynamics and the quality of tissue repair $[64,66]$.

Recent studies in vitro and in vivo also showed the proangiogenic activity on isolated proteins from viperids' venoms, which is effective in stimulating a better vascularization and nutrition potentially favorable for tissue repair $[67,68]$. Although LAPLA2 has supported angiogenesis in the proliferative stage, progressive reduction in vascular density and tissue cellularity occurred simultaneously, and a process that is expected as the remodeling phase is 

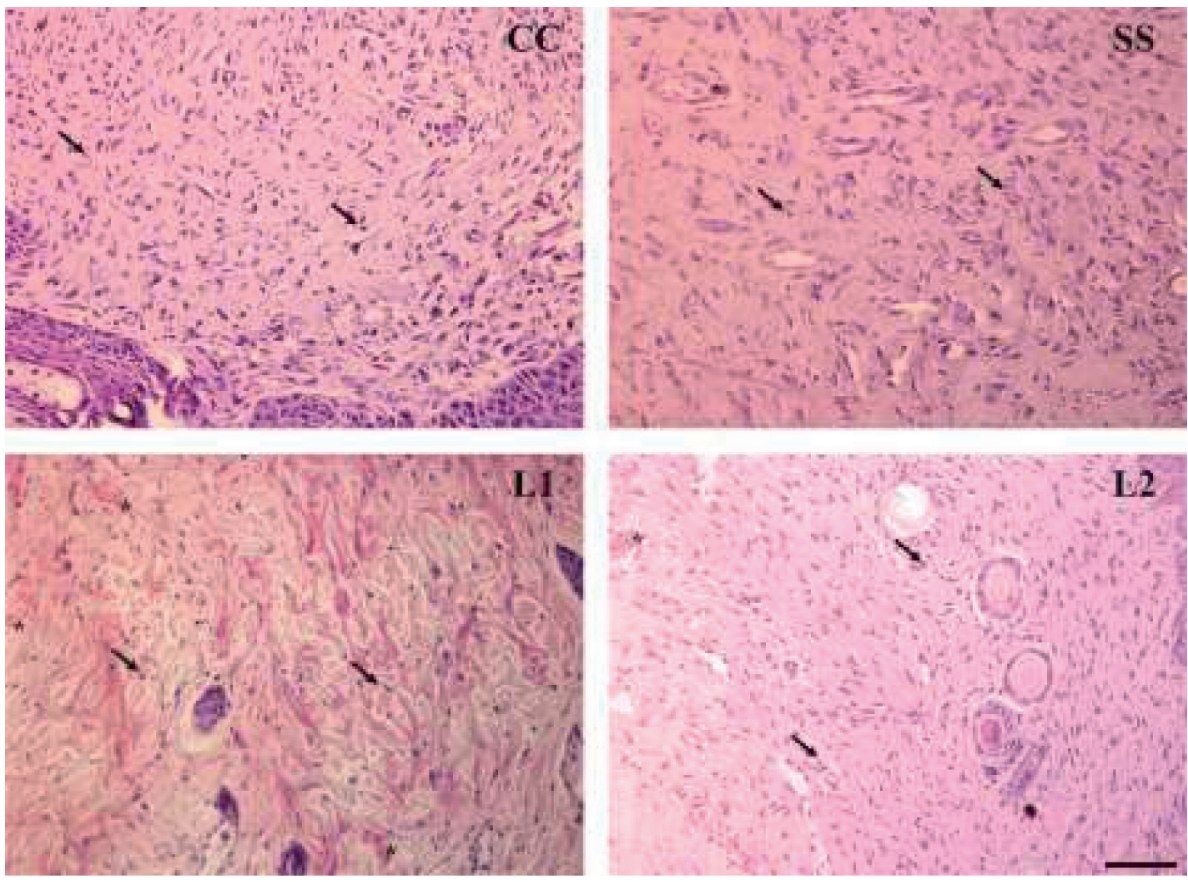

FIGURE 5: Representative photomicrographs of the scar tissue of mice treated with LAPLA2 isolated from snake venom. The images are representative of the scar tissue collected at day 12, indicating the most advanced healing process in all groups. C group: saline solution (0.9\%), SS group: silver sulfadiazine (1\%), L1 group: LAPLA2 (0.5\%), and L2 group: LAPLA2 (0.25\%). Tissue cellularity was more pronounced in the groups C and SS, while L1 and L2 animals exhibited marked distribution of cells (arrows) and vessels (asterisk). Bright field microscopy, hematoxylin and eosin staining, and scale bar: $20 \mu \mathrm{m}$.

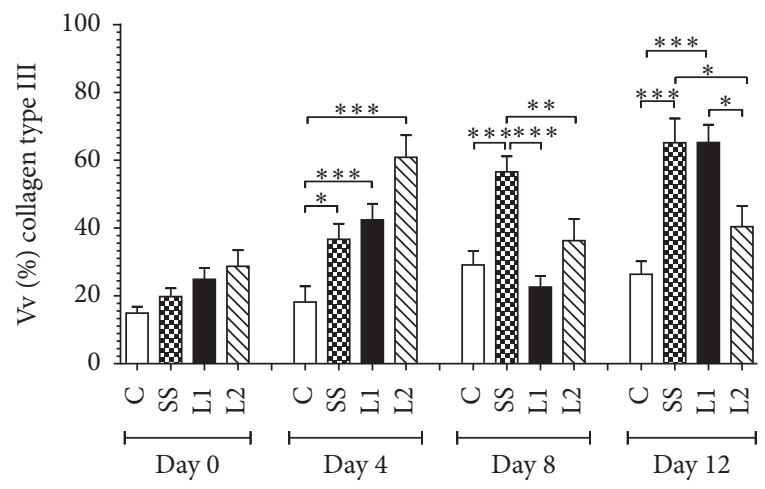

(a)

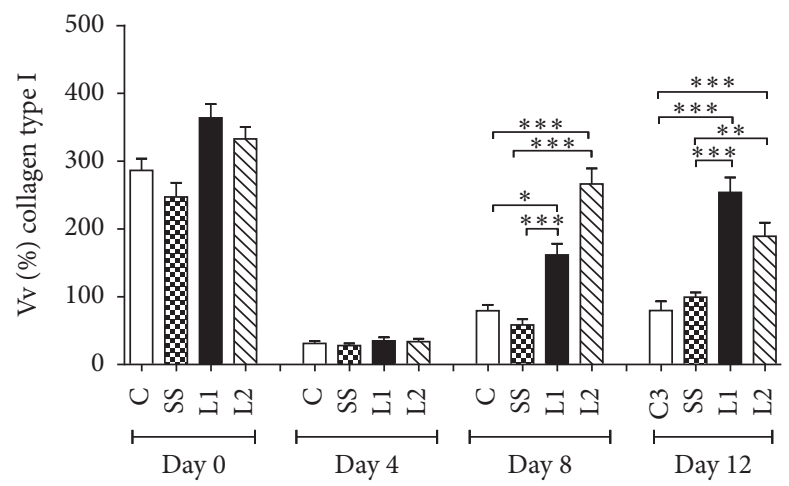

(b)

FIGURE 6: Proportion of type III (a) and type I (b) collagen fibers in the scar tissue of mice treated with LAPLA2 isolated from snake venom. C group: saline solution (0.9\%), SS group: silver sulfadiazine (1\%), L1 group: LAPLA2 (0.5\%), and L2 group: LAPLA2 (0.25\%). Data are presented as mean \pm standard deviation. Statistical differences ${ }^{*} P<0.05,{ }^{* *} P<0.01$, and ${ }^{* * *} P<0.001$.

established [69-71]. There is consistent evidence that after controlling the inflammation, the attenuation of trophic stimuli that occurs in response to lowering cytokine and growth factors levels activates the programmed death of a large cell population, especially leukocytes, fibroblasts, and endothelial cells $[72,73]$. This event ensures that the secreted extracellular matrix is properly rearranged, approximating the morphofunctional characteristics of the repairing tissue to those typically observed in healthy skin [74].

In addition, collagenous proteins are essential for providing skin tensile strength and modulating cell migration in the scar tissue [75]. Due to intense colagenogenesis that occurs in the remodeling phase of wound healing, the marked increase in tensile strength of scar tissue occurs in response to the broad replacement of type III by type I collagen fibers $[42,76]$. Similar to LAPLA2, the protein alternagin-C from Bothrops alternatus venom also is effective in stimulating colagenogenesis and scar tissue reorganization, increasing the deposition of type I collagen in rats' skin during wound healing [11]; in another work by Rabelo et al. [77], a disintegrin-like protein obtained from the venom of $B$. alternatus increased the collagen production in the fibrovascular tissue in mice. This effect was clearly observed in our study, since LAPLA2 from L. m. muta 


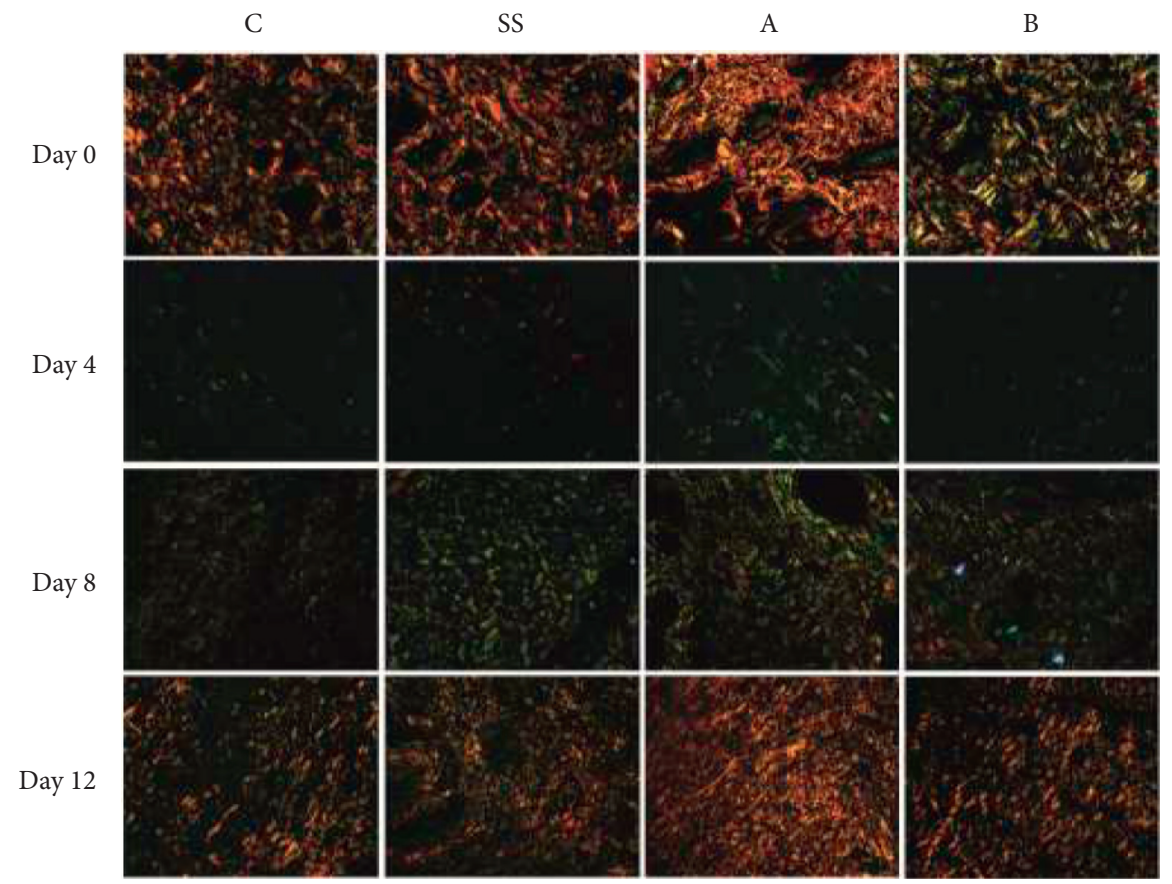

FIGURE 7: Representative photomicrographs obtained under polarizing microscopy demonstrate the distribution of collagen fibers in the scar tissue of rats treated with LAPLA2 isolated from snake venom. C group: saline solution (0.9\%), SS group: silver sulfadiazine (1\%), L1 group: LAPLA2 (0.5\%), and L2 group: LAPLA2 (0.25\%). Data are presented as mean \pm standard deviation.

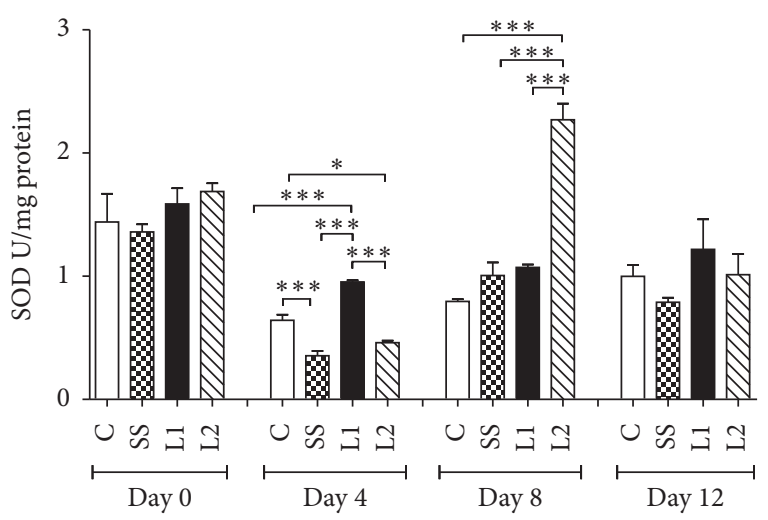

(a)

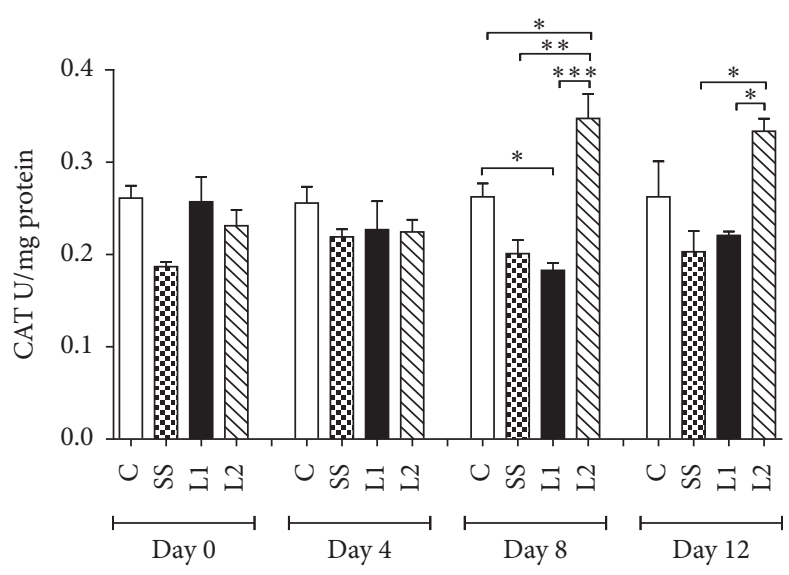

(b)

FIgURE 8: Time-dependent activity of superoxide dismutase (a) SOD and catalase (b) CAT in the scar tissue of mice treated with LAPLA2 isolated from snake venom. C group: saline solution (0.9\%), SS group: silver sulfadiazine (1\%), L1 group: LAPLA2 (0.5\%), and L2 group: LAPLA2 $(0.25 \%)$. Data are presented as mean \pm standard deviation. Statistical differences ${ }^{*} P<0.05,{ }^{* *} P<0.01$, and ${ }^{* * *} P<0.001$.

improved collagen maturation (type I/type II collagen ratio), which represents a direct morphological marker of wound closure.

Although the effects of LAPLA2 on skin biology is poorly understood, the modulation of oxidative processes in the scar tissue is potentially related with its healing properties observed in the present study. Animals treated with LAPLA2 showed an increased activity of the antioxidant enzymes SOD and CAT, which are important molecules involved in the modulation of tissue redox balance. Interestingly, this effect was beneficial in protecting the scar tissue against reactive tissue damage, since animals treated with LAPLA2 also exhibited decreased levels of lipid (i.e., MDA) and protein (i.e., CP) oxidation. The balance between the production of prooxidant molecules and antioxidant effectors is important for an efficient cutaneous repair [78]. When the tissue is damaged, the inflammatory process triggers an intense production of radical and nonradical prooxidant mediators (i.e., $\mathrm{OH}^{\bullet-}, \mathrm{O}_{2}^{\bullet-}, \mathrm{H}_{2} \mathrm{O}_{2}$, and $\mathrm{NO}$ ), which is directly associated to lipids, protein, and DNA oxidative damage that often culminates in disorganization of ECM and cell death $[70,79]$. Through inducing $\mathrm{H}_{2} \mathrm{O}_{2}$ catalysis, 


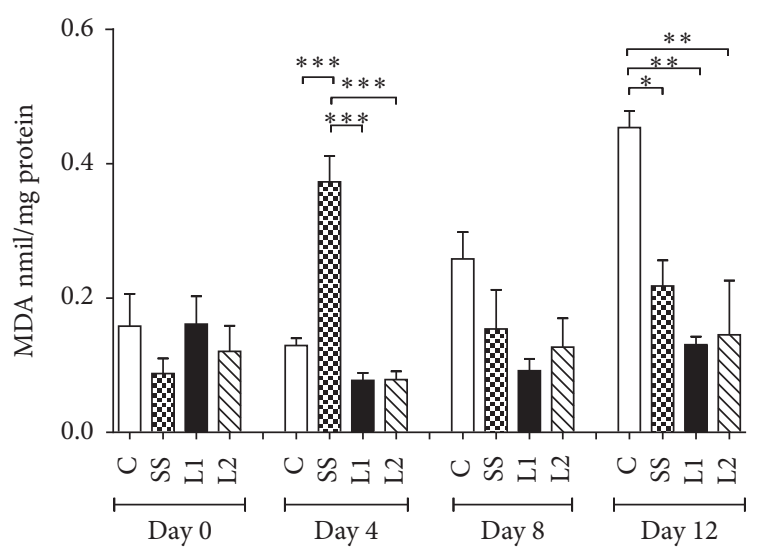

(a)

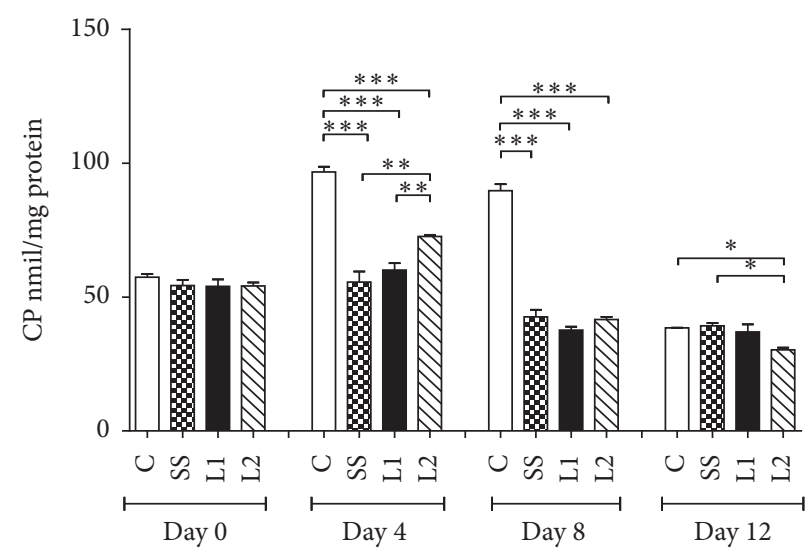

(b)

Figure 9: Malondialdehyde (a) MDA and carbonyl proteins and (b) CP in the scar tissue of mice treated with LAPLA2 isolated from snake venom. C group: saline solution (0.9\%), SS group: silver sulfadiazine (1\%), L1 group: LAPLA2 (0.5\%), and L2 group: LAPLA2 (0.25\%). Data are presented as mean \pm standard deviation. Statistical differences ${ }^{*} P<0.05,{ }^{* *} P<0.01$, and ${ }^{* * *} P<0.001$.

increased SOD levels are shown to potentiate the skin healing process [80]. Due to an improved redox balance, CAT and SOD also contribute to create a molecular microenvironment favorable to stimulating fibroblast proliferation, migration, and activation, which culminate in adequate production and organization of ECM and a fast wound closure [81, 82]. Similar antioxidant effects were obtained with proteins purified from the venom of the snake Naja naja, which proved to be effective in preventing lipid peroxidation by stimulating SOD and CAT activities [83].

By improving the redox balance in injured tissues, LAPLA2 has demonstrated intriguing and relevant therapeutic potential, which deserves to be investigated in detail, since prolongation of the inflammatory process and oxidative tissue damage are partly responsible for the chronicity of skin lesions $[84,85]$.

The sequence of the monomeric acidic phospholipase isolated from L. m. muta venom is homologous to LsPA-1, an acidic phospholipase isolated from L. stenophrys [86]. According to the venom's biochemical characteristics, measured through the proteomic analysis, the sequence of $L$. m. muta is more closely related to L. stenophrys than to other species from the same genus [17], since both share the sequence SGFWYYG. Our work also contributes to the knowledge of phospholipases found in Lachesis genus, through the identification of the newly shared sequences HLLQFGDLIDK, EICECDRDAAICFR, and SGFWYYGFYGCYCGLGGR, which show high homology with LAPLA2 and LsPA-1 proteins [17].

\section{Conclusion}

Taken together, our findings indicate that snake venom may be a relevant source for the identification of molecules with pharmacological applicability in regenerative medicine. Thus, by inducing proliferative, proangiogenic, colagenogenic, and antioxidant effects, as well as stimulating the maturation of collagen fibers, the acidic phospholipase A2 isolated from L. muta muta venom was effective in accelerating the rate of wound closure in a murine excisional wound model. In addition to increasing the rate of skin healing, the administration of this phospholipase was safe, since it did not induce toxicity on fibroblasts and keratinocytes, integumentary cells essential for the repair of injured tissue from processes of reepithelization and reconstitution of the conjunctive matrix. Thus, LAPLA2 constitutes a promising and interesting molecule potentially useful in regenerative medicine to potentiate skin wound healing.

\section{Data Availability}

The data used to support the findings of this study are included within the article.

\section{Ethical Approval}

All the procedures used in this study were approved by the Ethics Committee of Animal Experimentation of the Federal University of Viçosa (registration 365/2015).

\section{Conflicts of Interest}

The authors declare no conflicts of interest.

\section{Authors' Contributions}

All authors equally contributed to the research and/or manuscript preparation and approved its final version.

\section{Acknowledgments}

This work was supported by Fundação de Amparo à Pesquisa do Estado de Minas Gerais (FAPEMIG PPM 0068717), Conselho Nacional de Desenvolvimiento Científico e Tecnológico (CNPq PQ 305093/2017-7, 303972/2017-3, and MCTIC 408503/2018-1), and Coordenação de Aperfeiçoamento de Pessoal de Nível Superior (CAPES Finance code 001). 


\section{Supplementary Materials}

Table S1: peptides (HLLQFGDLIDK), (EICECDRDAAICFR), and (SGFWYYGFYGCYCGLGGR) were fragmented and aligned with the acidic phospholipase A2 (PA2A) sequence of Lachesis stenophrys. Figure S1: multiple alignment of LAPLA2 partial amino acid sequences with five homologous phospholipases A2 sequence from snake venoms. The UniProtKB access codes and the species for the acidic enzyme sequences are shown in boldfaces. Sequences are aligned by MUSCLE in MEGA v7.025 software. Identical amino acid positions are in yellow. (Supplementary Materials)

\section{References}

[1] J. Zhou, D. Yao, Z. Qian et al., "Bacteria-responsive intelligent wound dressing: simultaneous in situ detection and inhibition of bacterial infection for accelerated wound healing," Biomaterials, vol. 161, pp. 11-23, 2018.

[2] M. A. Mofazzal Jahromi, P. Sahandi Zangabad, S. M. Moosavi Basri et al., "Nanomedicine and advanced technologies for burns: preventing infection and facilitating wound healing," Advanced Drug Delivery Reviews, vol. 123, pp. 33-64, 2018.

[3] C. K. Sen, G. M. Gordillo, S. Roy et al., "Human skin wounds: a major and snowballing threat to public health and the economy," Wound Repair and Regeneration, vol. 17, no. 6, pp. 763-771, 2009.

[4] R. G. Frykberg and J. Banks, "Challenges in the treatment of chronic wounds," Advances in Wound Care, vol. 4, no. 9, pp. 560-582, 2015.

[5] S. R. Nussbaum, M. J. Carter, C. E. Fife et al., "An economic evaluation of the impact, cost, and medicare policy implications of chronic nonhealing wounds," Value Heal, vol. 21, no. 1, pp. 27-32, 2018.

[6] R. P. Samy, M. Kandasamy, P. Gopalakrishnakone et al., "Wound healing activity and mechanisms of action of an antibacterial protein from the venom of the eastern diamondback rattlesnake (Crotalus adamanteus)," PLoS One, vol. 9, no. 2, Article ID e80199, 2014.

[7] D. H. M. Dam, S. A. Jelsma, and A. S. Paller, "Impaired wound healing in diabetic ulcers: accelerated healing through depletion of ganglioside," Wound Healing, vol. 1, pp. 167-175, 2018.

[8] M. Mahboubi, M. Taghizadeh, T. Khamechian et al., "The wound healing effects of herbal cream containing Oliveria decumbens and Pelargonium graveolens essential oils in diabetic foot ulcer model," World Journal of Plastic Surgery, vol. 7, no. 1, pp. 45-50, 2018.

[9] N. Lebonvallet, B. Laverdet, L. Misery, A. Desmoulière, and D. Girard, "New insights into the roles of myofibroblasts and innervation during skin healing and innovative therapies to improve scar innervation," Experimental Dermatology, vol. 27, no. 9, pp. 950-958, Sep. 2018.

[10] X. Cao, Y. Wang, C. Wu et al., "Cathelicidin-OA1, a novel antioxidant peptide identified from an amphibian, accelerates skin wound healing," Science Reports, vol. 8, no. 1, p. 943, 2018.

[11] E. M. C. Sant'Ana, C. M. C. P. Gouvêa, J. L. Q. Durigan et al., "Rat skin wound healing induced by alternagin-C, a disintegrin-like, Cys-rich protein from Bothrops alternatus venom," International Wound Journal, vol. 8, no. 3, pp. 245-252, 2011.
[12] R. Thakur, P. Chattopadhyay, and A. K. Mukherjee, "The wound healing potential of a proangiogenic peptide purified from Indian Russell's viper (Daboia russelii) venom," Toxicon, vol. 165, pp. 78-82, 2019.

[13] M. A. Amin and I. T. Abdel-Raheem, "Accelerated wound healing and anti-inflammatory effects of physically cross linked polyvinyl alcohol-chitosan hydrogel containing honey bee venom in diabetic rats," Archives of Pharmacal Research, vol. 37, no. 8, pp. 1016-1031, 2014.

[14] J. Tang, H. Liu, C. Gao et al., "A small peptide with potential ability to promote wound healing," PLoS One, vol. 9, no. 3, 2014.

[15] Y. N. Utkin, "Animal venom studies: current benefits and future developments," World Journal of Biological Chemistry, vol. 6, no. 2, pp. 28-34, 2015.

[16] Y. Wang, Z. Zhang, L. Chen et al., "Cathelicidin-BF, a snake cathelicidin-derived antimicrobial peptide, could Be an excellent therapeutic agent for acne vulgaris," PLoS One, vol. 6, no. 7, Article ID e22120, 2011.

[17] L. Sanz, J. Escolano, M. Ferretti et al., "Snake venomics of the South and Central American Bushmasters. Comparison of the toxin composition of Lachesis muta gathered from proteomic versus transcriptomic analysis," Journal of Proteomics, vol. 71, no. 1, pp. 46-60, 2008.

[18] K. C. da Silva Cunha, A. L. Fuly, and E. Giestal de Araujo, "A phospholipase A2 isolated from Lachesis muta snake venom increases the survival of retinal ganglion cells in vitro," Toxicon, vol. 57, no. 4, pp. 580-585, 2011.

[19] D. C. S. Damico, T. Vassequi-Silva, F. D. Torres-Huaco, A. C. C. Nery-Diez, R. C. G. de Souza, S. L. Da Silva et al., "LmrTX, a basic PLA2 (D49) purified from Lachesis muta rhombeata snake venom with enzymatic-related antithrombotic and anticoagulant activity," Toxicon, vol. 60, no. 5, pp. 773-781, 2012.

[20] R. H. Schaloske and E. A. Dennis, "The phospholipase A2 superfamily and its group numbering system," Biochimica et Biophysica Acta (BBA) - Molecular and Cell Biology of Lipids, vol. 1761, no. 11, pp. 1246-1259, 2006.

[21] R. Doley, "Snake venom phospholipase A2 enzymes," in Handbook of Venoms and Toxins of Reptiles, in Handbook of Venoms And Toxins of Reptiles, S. P. Mackessy, Ed., pp. 173-205, 2010.

[22] B. Lomonte, Y. Angulo, L. Calderón, and C. Rica, "An overview of lysine- 49 phospholipase A2 myotoxins from crotalid snake venoms and their structural determinants of myotoxic action," Toxicon, vol. 42, no. 8, pp. 885-901, 2003.

[23] B. Lomonte and J. Rangel, "Snake venom Lys49 myotoxins: from phospholipases A2 to nonenzymatic membrane disruptors," Toxicon, vol. 60, no. 4, pp. 520-530, 2012.

[24] E. Jiménez-Charris, L. Montealegre-Sánchez, L. SolanoRedondo, F. Castro-Herrera, L. Fierro-Pérez, and B. Lomonte, "Divergent functional profiles of acidic and basic phospholipases A2 in the venom of the snake Porthidium lansbergii lansbergii," Toxicon, vol. 119, pp. 289-298, 2016.

[25] E. Flores Sánchez, A. Magalhães, F. R. Mandelbaum, and C. R. Diniz, "Purification and characterization of the hemorrhagic factor II from the venom of the bushmaster snake (Lachesis muta muta)," Biochimica et Biophysica Acta (BBA)General Subjects, vol. 1074, no. 3, pp. 347-356, 1991.

[26] O. H. Lowry, N. J. Rosebrough, A. L. Farr, and R. J. Randall, "Protein measurement with the folin phenol reagent," Journal of Biological Chemistry, vol. 193, no. 1, pp. 265-275, 1951. 
[27] U. K. Laemmli, "Cleavage of structural proteins during the assembly of the head of bacteriophage T4," Nature, vol. 227, no. 5259, pp. 680-685, 1970.

[28] J. V Olsen, M. Mann, A. Shevchenko, H. Tomas, and J. Havlis, "In-gel digestion for mass spectrometric characterization of proteins and proteomes," Nature Protocols, vol. 1, no. 6, pp. 2856-2860, 2007.

[29] A. Keller, A. I. Nesvizhskii, E. Kolker, and R. Aebersold, "Empirical statistical model to estimate the accuracy of peptide identifications made by MS/MS and database search," Analytical Chemistry, vol. 74, no. 20, pp. 5383-5392, 2002.

[30] A. I. Nesvizhskii, A. Keller, E. Kolker, and R. Aebersold, "A statistical model for identifying proteins by tandem mass spectrometry," Analytical Chemistry, vol. 75, no. 17, pp. 4646-4658, 2003.

[31] R. C. Edgar, "MUSCLE: multiple sequence alignment with high accuracy and high throughput," Nucleic Acids Research, vol. 32, no. 5, pp. 1792-1797, 2004.

[32] K. Tamura, G. Stecher, D. Peterson, A. Filipski, and S. Kumar, "MEGA6: molecular evolutionary genetics analysis version 6.0," Molecular Biology and Evolution, vol. 30, no. 12, pp. 2725-2729, 2013.

[33] D. T. Jones, W. R. Taylor, and J. M. Thornton, "The rapid generation of mutation data matrices from protein sequences," Bioinformatics, vol. 8, no. 3, pp. 275-282, 1992.

[34] D. C. S. Damico, J. M. Nascimento, B. Lomonte et al., "Сytotoxicity of Lachesis muta muta snake (bushmaster) venom and its purified basic phospholipase A2 (LmTX-I) in cultured cells," Toxicon, vol. 49, no. 5, pp. 678-692, 2007.

[35] R. V. Gonçalves, R. D. Novaes, M. M. Sarandy et al., " $5 \alpha-$ Dihydrotestosterone enhances wound healing in diabetic rats," Life Sciences, vol. 152, pp. 67-75, 2016.

[36] A. H. Fischer, K. A. Jacobson, J. Rose, and J. Zeller, "Hematoxylin and eosin staining of tissue and cell sections," Cold Spring Harbor Protocols, vol. 5, no. 3, Article ID pdbprot4986, 2008.

[37] M. Leclere, M. Desnoyers, G. Beauchamp, and J.-P. Lavoie, "Comparison of four staining methods for detection of mast cells in equine bronchoalveolar lavage fluid," Journal of Veterinary Internal Medicine, vol. 20, no. 2, pp. 377-381, 2006.

[38] L. C. U. Junqueira, G. Bignolas, and R. R. Brentani, "Picrosirius staining plus polarization microscopy, a specific method for collagen detection in tissue sections," The Histochemical Journal, vol. 11, no. 4, pp. 447-455, 1979.

[39] R. Lattouf, R. Younes, D. Lutomski et al., "Picrosirius red staining," Journal of Histochemistry \& Cytochemistry, vol. 62, no. 10, pp. 751-758, 2014.

[40] R. V. Gonçalves, R. D. Novaes, M. C. Cupertino et al., "Bathysa cuspidata extract modulates the morphological reorganization of the scar tissue and accelerates skin wound healing in rats: a time-dependent study," Cells Tissues Organs, vol. 199 , no. 4 , pp. 266-277, 2014

[41] C. A. Mandarim-de-lacerda and " Redalyc, "Stereological tools in biomedical research," Anais da Academia Brasileira de Ciências, vol. 75, no. 4, pp. 469-486, 2003.

[42] R. V. Gonçalves, J. M. S. Mezêncio, G. P. Benevides et al., "Effect of gallium-arsenide laser, gallium-aluminum-arsenide laser and healing ointment on cutaneous wound healing in Wistar rats," Brazilian Journal of Medical and Biological Research, vol. 43, no. 4, pp. 350-355, 2010.

[43] D. Novaes, R. V Gonc, L. P. Matta et al., "The energy density of laser light differentially modulates the skin morphological reorganization in a murine model of healing by secondary intention," International Journal of Experimental Pathology, vol. 95, no. 2, pp. 138-146, 2014.

[44] I. A. Siddiqui, S. Raisuddin, and Y. Shukla, "Protective effects of black tea extract on testosterone-induced oxidative damage in prostate," Cancer Letter, vol. 227, no. 2, pp. 125-132, 2005.

[45] H. Aebi, "Catalase in vitro," Methods Enzymology, vol. 105, pp. 121-126, 1984.

[46] M. M. Bradford, “A rapid and sensitive method for quantitation of microgram quantities of protein utilizing the principle of protein-dye-binding," Analytical Biochemistry, vol. 72 , pp. $248-254,1976$.

[47] J. M. C. Gutteridge and B. Halliwell, "The measurement and mechanism of lipid peroxidation in biological systems," Trends in Biochemical Science, vol. 15, no. 4, pp. 129-135, 1990.

[48] K. Jana, A. Dutta, P. Chakraborty et al., "Alpha-lipoic acid and $\mathrm{N}$-acetylcysteine protects intensive swimming exercise-mediated germ-cell depletion, prooxidant generation, and alteration of steroidogenesis in rat testis," Molecular Reproduction and Development, vol. 18, no. 9, pp. 833-850, 2014.

[49] D. L. Menaldo, C. P. Bernardes, K. F. Zoccal et al., "Immune cells and mediators involved in the inflammatory responses induced by a P-I metalloprotease and a phospholipase A2 from Bothrops atrox venom," Molecular Immunology, vol. 85, pp. 238-247, 2017.

[50] J. Fernández, J. M. Gutiérrez, Y. Angulo et al., "Isolation of an acidic phospholipase A2from the venom of the snake Bothrops asper of Costa Rica: biochemical and toxicological characterization," Biochimie, vol. 92, no. 3, pp. 273-283, 2010.

[51] L. B. Jiménez-Charris, L. Montealegre-Sánchez, L. SolanoRedondo, F. Castro-Herrera, and L. Fierro-Pérez, "Divergent functional profiles of acidic and basic phospholipases A 2 in the venom of the snake Porthidium lansbergii lansbergii Eli e," Toxicon, vol. 119, pp. 289-298, 2016.

[52] S. Sawan, T. Yaacoub, S. Hraoui-Bloquet et al., "Montivipera bornmuelleri venom selectively exhibits high cytotoxic effects on keratinocytes cancer cell lines," Experimental and Toxicologic Pathology, vol. 69, no. 4, pp. 173-178, 2017.

[53] D. Paixão-Cavalcante, C. W. van den Berg, M. de Freitas Fernandes-Pedrosa, R. M. Gonçalves de Andrade, and D. V Tambourgi, "Role of matrix metalloproteinases in $\mathrm{HaCaT}$ keratinocytes apoptosis induced by Loxosceles venom sphingomyelinase D," Journal of Investigative Dermatology, vol. 126, no. 1, pp. 61-68, 2006.

[54] E. Jin, T.-H. Kim, S. Han, and S.-W. Kim, "Amniotic epithelial cells promote wound healing in mice through high epithelialization and engraftment," Journal of Tissue Engineering and Regenerative Medicine, vol. 10, no. 7, pp. 613-622, Jul. 2016.

[55] S. Kazemi-Darabadi, F. Sarrafzadeh-Rezaei, A. A. Farshid, and B. Dalir-Naghadeh, "Allogenous skin fibroblast transplantation enhances excisional wound healing following alloxan diabetes in sheep, a randomized controlled trial," International Journal of Surgery, vol. 12, no. 8, pp. 751-756, 2014.

[56] A. Oikarinen and M. Kallioinen, "A biochemical and immunohistochemical study of collagen in sun-exposed and protected skin," Photodermatology, vol. 6, no. 1, pp. 24-31, 1989.

[57] I. Fuentes-Calvo, A. M. Blázquez-Medela, N. Eleno et al., "HRas isoform modulates extracellular matrix synthesis, proliferation, and migration in fibroblasts," American Journal of Physiology, vol. 302, no. 4, pp. C686-C697, 2011.

[58] C. Theoret, "Physiology of wound healing," 2016. 
[59] C. Noli and A. Miolo, "The mast cell in wound healing," Veterinary Dermatology, vol. 12, no. 6, pp. 303-313, December. 2001.

[60] T. A. Wilgus, "Immune cells in the healing skin wound: influential players at each stage of repair," Pharmacological Research, vol. 58, no. 2, pp. 112-116, 2008.

[61] I. Puxeddu, A. M. Piliponsky, I. Bachelet, and F. Levi-Schaffer, "Mast cells in allergy and beyond," The International Journal of Biochemistry \& Cell Biology, vol. 35, no. 12, pp. 1601-1607, 2003.

[62] A. Tellechea, E. C. Leal, A. Kafanas et al., "Mast cells regulate wound healing in diabetes," Diabetes, vol. 65, no. 7, p. 2006, 2019.

[63] Y. Iba, A. Shibata, M. Kato, and T. Masukawa, "Possible involvement of mast cells in collagen remodeling in the late phase of cutaneous wound healing in mice," International Immunopharmacology, vol. 4, no. 14, pp. 1873-1880, 2004.

[64] K. Nishida, A. Hasegawa, S. Yamasaki et al., "Mast cells play role in wound healing through the ZnT2/GPR39/IL-6 axis," Science Reports, vol. 9, no. 1, p. 10842, 2019.

[65] N. Shiota, Y. Nishikori, E. Kakizoe et al., "Pathophysiological role of skin mast cells in wound healing after scald injury: study with mast cell-deficient $\mathrm{W} / \mathrm{Wv}$ mice," International Archives of Allergy and Immunology, vol. 151, no. 1, pp. 80-88, 2009.

[66] J. Succar, G. Giatsidis, N. Yu et al., "Mouse mast cell protease4 recruits leukocytes in the inflammatory phase of surgically wounded skin," Advances in Wound Care, vol. 8, no. 10, pp. 469-475, 2019.

[67] O. H. P. Ramos, C. H. B. Terruggi, J. U. Ribeiro et al., "Modulation of in vitro and in vivo angiogenesis by alternagin- $\mathrm{C}$, a disintegrin-like protein from Bothrops alternatus snake venom and by a peptide derived from its sequence," Archives of Biochemistry and Biophysics, vol. 461, no. 1, pp. 1-6, 2007.

[68] A. K. Mukherjee, S. Chatterjee, S. Majumder et al., "Characterization of a proangiogenic, novel peptide from Russell's viper (Daboia russelii russelii) venom," Toxicon, vol. 77, pp. 26-31, 2014.

[69] Y. M. Elçin, V. Dixit, and G. Gitnick, "Extensive in vivo angiogenesis following controlled release of human vascular endothelial cell growth factor: implications for tissue engineering and wound healing," Artificial organ, vol. 25, no. 7, pp. 558-565, Jul. 2001.

[70] S. Guo and L. A. DiPietro, "Factors affecting wound healing," Journal of Dental Research, vol. 89, no. 3, pp. 219-229, Feb. 2010.

[71] J. Zhang, C. Chen, B. Hu et al., "Exosomes derived from human endothelial progenitor cells accelerate cutaneous wound healing by promoting angiogenesis through Erk1/2 signaling," International Journal of Biological Sciences, vol. 12, no. 12, pp. 1472-1487, 2016.

[72] S. E. Gill and W. C. Parks, "Metalloproteinases and their inhibitors: regulators of wound healing," The International Journal of Biochemistry \& Cell Biology, vol. 40, no. 6, pp. 1334-1347, 2008.

[73] J. Ding and E. E. Tredget, "The role of chemokines in fibrotic wound healing," Advances in Wound Care, vol. 4, no. 11, pp. 673-686, 2015.

[74] V. A. Nguyen and M. A. Soulika, "The dynamics of the skin's immune system," International Journal of Molecular Sciences, vol. 20, no. 8, 2019.

[75] I. Fuentes-Calvo, A. M. Blázquez-Medela, N. Eleno et al., "HRas isoform modulates extracellular matrix synthesis, proliferation, and migration in fibroblasts," American Journal of Physiology, vol. 302, no. 4, pp. C686-C697, 2012.

[76] R. Thakur, N. Jain, R. Pathak, and S. S. Sandhu, "Practices in wound healing studies of plants," Evidence-Based Complementary and Alternative Medicine, vol. 2011, p. 17, 2011.

[77] L. F. G. Rabelo, B. A. Ferreira, S. R. Deconte et al., "Alternagin- $\mathrm{C}$, a disintegrin-like protein from Bothrops alternatus venom, attenuates inflammation and angiogenesis and stimulates collagen deposition of sponge-induced fibrovascular tissue in mice," International Journal of Biological Macromolecules, vol. 140, pp. 653-660, 2019.

[78] J. Limón-Pacheco and M. E. Gonsebatt, "The role of antioxidants and antioxidant-related enzymes in protective responses to environmentally induced oxidative stress," Mutation Research-Genetic Toxicology and Environmental Mutagen, vol. 674, no. 1-2, pp. 137-147, 2009.

[79] U. Panich, G. Sittithumcharee, N. Rathviboon, and S. Jirawatnotai, "Ultraviolet radiation-induced skin aging: the role of DNA damage and oxidative stress in epidermal stem cell damage mediated skin aging," Stem Cells International, vol. 2016, p. 14, 2016.

[80] A. Shukla, A. M. Rasik, and B. N. Dhawan, "Asiaticoside induced elevation of antioxidant levels in healing wound," Phytotherapy Research, vol. 13, pp. 50-54, 1998.

[81] T. Fukai and M. Ushio-Fukai, "Superoxide dismutases: role in redox signaling, vascular function, and diseases," Antioxid. Redox Signal.vol. 15, no. 6, pp. 1583-1606, 2011.

[82] F. Bilgen, A. Ural, E. B. Kurutas, and M. Bekerecioglu, "The effect of oxidative stress and Raftlin levels on wound healing," International Wound Journal, vol. 16, no. 5, pp. 1178-1184, 2019.

[83] T. Das, S. Bhattacharya, B. Halder et al., "Cytotoxic and antioxidant property of a purified fraction (NN-32) of Indian Naja naja venom on Ehrlich ascites carcinoma in BALB/C mice," Toxicon, vol. 57, no. 7-8, pp. 1065-1072, 2011.

[84] J. L. Evans, I. D. Goldfine, B. A. Maddux, and G. M. Grodsky, "Oxidative stress and stress-activated signaling pathways: a unifying hypothesis of type 2 diabetes," Endocrine Reviews, vol. 23, no. 5, pp. 599-622, 2002.

[85] C. Dunnill, T. Patton, J. Brennan et al., "Reactive oxygen species (ROS) and wound healing: the functional role of ROS and emerging ROS-modulating technologies for augmentation of the healing process," International Wound Journal, vol. 14, no. 1, pp. 89-96, 2017.

[86] E. B. de Assis, M. I. Estevão-Costa, A. do C. Valentim et al., "Purification and complete primary structure of the first PLA2 from Lachesis stenophrys (the central American bushmaster) snake venom," Protein Science, vol. 27, pp. 327-333, 2008. 